\title{
Canine distemper in Siberian tiger cubs from Zagreb ZOO: case report
}

\author{
Dean Konjević ${ }^{1}$, Ruža Sabočanec ${ }^{1}$, Željko Grabarević $^{1}$, Andreas Zurbriggen ${ }^{2}$, \\ Ingeborg Bata ${ }^{3}$, Ana Beck ${ }^{1}$, Andrea Gudan Kurilj ${ }^{1}$, Denis Cvitković ${ }^{1}$ \\ ${ }^{1}$ Veterinary Faculty, University of Zagreb, Croatia \\ ${ }^{2}$ Vetsuisse Faculty, University of Bern, Switzerland \\ ${ }^{3}$ Zagreb ZOO, Croatia \\ Received June 5, 2009 \\ Accepted September 21, 2010
}

\begin{abstract}
Canine distemper is a contagious, potentially lethal disease of mainly domestic and wild canids, but also of many other mammalian species including large felids. In February 2004, two Siberian tiger (Panthera tigris altaica) cubs at the age of six months died at the Zagreb ZOO. The animals were presented for necropsy with two days history of severe digestive disorders, characterized mainly by haemathemesis. Dissections revealed catarrhal to pseudomembranous gastroenteritis (depending on the animal) accompanied with haemorrhagic oedema of the lungs. Necrotic tonsillitis and disseminated depletion of the lymphocytes were the most prominent histological findings in both examined animals, while intranuclear and intracytoplasmatic inclusion bodies were found in the samples of the tongues and intestines. Representative portions of the livers, intestines, tonsils and lymph nodes were submitted for bacteriological and mycological analysis. The presence of Clostridium spp., Campylobacter coli and Escherichia coli was detected in gut samples, coli-like bacteria were found in samples of liver, tonsils and lymph nodes, while Candida sp. was found in the gut and pharynx samples. Toxicological analysis excluded anticoagulant and organophosphorous intoxication as the cause of death. Immunohistochemical analysis was positive for canine distemper virus. Based on all this, epizootiological, clinical and additional findings, canine distemper was recognized as the cause of the observed condition in these animals.
\end{abstract}

Large felids, digestive disorders, virus, immunohistochemistry

Canine distemper (CD) is a worldwide infectious disease of mainly domestic dogs, but also of a broad spectrum of other species including large felids (Deem et al. 2000). The disease is caused by a negative-stranded morbilivirus of the Paramyxoviridae family that is closely related to the measles and phocine distemper virus. Despite the fact that CD is probably one of the best examples of a disease that has proved capable of compromising the conservation of several wild carnivore species (i.e. Williams et al. 1988; RoelkeParker et al. 1996; Barret 1999; Kennedy et al. 2000; van de Bildt et al. 2002), it has been repeatedly found that canine distemper virus (CDV) historically is not pathogenic in lions and tigers. This hypothesis was tested by Myers et al. (1997) who examined 42 cases of large cat mortalities in Switzerland and found evidence that 19 samples were positive (the oldest positive sample originated from 1972), indicating that CDV infections in lions and tigers are older and more widespread than previously thought. In the present report we describe clinical, pathological, histological and immunohistochemical findings in a case of naturally occurring canine distemper in captive Siberian tiger cubs.

\section{Case report and findings}

During February 2004, zoo-keepers reported that 2 out of 3 Siberian tiger (Panthera tigris altaica) cubs at the age of 6 months were exhibiting signs of gastrointestinal disorders. The cubs were immediately separated from their mother and the third cub. Their condition progressively deteriorated, with haemathemesis as the most prominent clinical symptom. The observed clinical condition was preliminary diagnosed as anticoagulant intoxication

Address for correspondence:

MVDr. Dean Konjević, Ph.D, Dipl. ECZM (Wildlife Population Health)

University of Zagreb, Veterinary Faculty

Phone: +38512390156

Heinzelova 55, 10000 Zagreb, Croatia 
and prescribed therapy included vitamin $\mathrm{K}_{1}$ (Konakion $^{\circledR}$, Roche, Switzerland), H2 agonist to prevent gastric ulcers (Peptoran ${ }^{\circledR}$, Pliva, Croatia) and trimethoprim-sulphadiazine combination (Trimetosul ${ }^{\circledR} 48 \%$, Pliva, Croatia) as supportive antibacterial therapy. Despite the therapy, one cub died 2 days after the onset of clinical signs, and the other survived for 2 more days. The third cub that remained with the mother exhibited no signs of disease and both of them received a 5-day full therapy. Necropsies revealed ulcerative pharyngitis and tonsillitis, and catarrhal to pseudomembranous gastroenteritis (depending on the animal) accompanied with haemorrhagic oedema of the lungs. Multifocal necroses were found on the liver and pancreas. Along with microscopic lesions underlying the described gross changes, necrotic tonsillitis and disseminated depletion of lymphocytes were the most prominent findings in both examined animals. Intracytoplasmatic and intranuclear inclusion bodies were recognized in the tongue and intestines (Plate III, Fig. 1). Representative portions of the liver, intestines, tonsils and lymph nodes were submitted for bacteriological and mycological analysis. The presence of Clostridium spp., Campylobacter coli and Escherichia coli was detected in gut samples, coli-like bacteria were found in samples of the liver, tonsils and lymph nodes, while Candida sp. was found in the gut and pharynx samples. Toxicological analysis of the samples of blood and gastric content excluded anticoagulant and organophosphorous intoxication as the cause of death. Two years later, paraffin embedded samples of tiger organs were sent to the University of Bern for immunohistochemical analysis (IHC) with positive labelling obtained for the CDV antigen (Plate III, Fig. 2). In brief, the nucleocapsid (N) protein of CDV was detected using a monoclonal antibody D110 diluted 1:2 in TBS. We used goat-anti-mouse antibody diluted 1:40 in TBS as a secondary antibody. Sections were deparaffinized, rehydrated, peroxidase blocked, demasked and incubated with primary and secondary antibodies and visualized with peroxidase antiperoxidase reaction. Due to the similarities in some clinical and pathological findings between infections caused by canine parvovirus and CDV, an IHC staining for parvovirus was performed with negative results. Based on all this, epizootiological, clinical and additional findings, canine distemper was recognized as the cause of the observed condition in the respective animals.

\section{Discussion}

Major attention has only been paid to CDV infections in large felids after the epidemics in California (Appel et al. 1994) and Serengeti (Roelke-Parker et al. 1996). However, the disease was probably occurring some time before that, because CD in large felids was for the first time suspected in 1950 when two young lions died with typical neurological signs (Piat 1950). The main clinical symptoms in infected felids include either acute neurologic involvement or progressive intestinal and respiratory signs that, in a case of prolonged course, may lead to neurologic disease. Gross and microscopic lesions in felids infected with CDV are rare when compared to canids (Munson 2001). Gastrointestinal signs in large felids include anorexia and diarrhoea that is sometimes haemorrhagic, as was observed also in our case. Similarly to our findings, intracytoplasmic and intranuclear inclusion bodies can be found in many organs, while generalized depletion of lymphoid organs and associated immunosuppression is a common manifestation of CD (for a review see Beineke et al. 2009). Despite the fact that CDV can cause both intranuclear and intracytoplasmatic inclusion bodies, there is still a possibility that some other viruses participated in their formation. For example, adenoviruses can cause intranuclear inclusion bodies and are occasionally present in the felids (Lakatos et al. 1999). However, based on all other analyses we do not consider adenoviruses as etiological agent of this condition. The main route of virus transmission is aerosol or fomites with the initial infection occurring in the epithelium and lymphoid tissue of the nasopharynx. As several strains of CDV are 
known to exist, with different pathogenicity in different species, it is highly possible that certain local strains of the CDV cause disease in large felids and not just one special strain (Barrett 1999). This is evident from the fact that the CDV that caused disease in North American lions is the same as the one isolated from racoons, while the strain isolated from African lions matches the strain isolated from hyenas and domestic dogs. This conclusion, especially based on the observed line of events during the Serengeti outbreak, indicates that a certain adaptation period is required between the virus transmission to another species and the onset of the epidemic form of the disease. In this initial stage, the virus probably requires certain predisposing factors to cause the clinically manifested illness. This, along with the fact that $\mathrm{CD}$ is frequently a subclinical infection, could be an answer to the dilemma about why some large felids develop the disease while the rest of the group remain healthy (Myers et al. 1997). In the case of the Zagreb ZOO tigers, the history of neonatal health problems in the cubs in question (low body weight, rachitic animals, etc.) that were overcome by time, represent a potential predisposition to CDV infection (considering that the adult animals and the third cub remained clinically healthy). This is further emphasized by the rapid onset and short duration of the disease, without the involvement of CNS. In most felids, the clinical duration of the disease ranges from 1 day to several weeks and is usually fatal. Regarding the possible source of virus, one of the explanations are zoo-keepers that own domestic dogs and could carry the virus on their clothes (virus is relatively unstable in the environment requiring closer contact); another is the abundant free-living marten population as it is known that martens are highly susceptible to CDV (Deem et al. 2000; Frölich et al. 2000). The third possibility are subclinically infected adult tigers and lions (kept in an adjacent cage) that could spread viruses to their environment. In one example, Ramanathan et al. (2007) analysed blood samples from 56 apparently healthy captive Asiatic lions (Panthera leo persica) for the presence of antibodies against CDV, feline parvovirus (FPV), feline immunodeficiency virus (FIV) and feline leukemia virus (FeLV). Among them, 49 were positive for CDV and all 56 for FPV. Such a high prevalence of subclinically infected captive lions gives rise to the possibility of transmission of the virus to cubs, especially if it is known that CDV is relatively unstable in the environment, requiring close contact between infected and non-infected animals.

\section{Acknowledgment}

The study was supported by grants Nos. 053-0532264-2260 and 053-0532400-2399, of the Ministry of Science, Education and Sport of the Republic of Croatia.

\section{References}

Appel MJG, Yates RA, Foley GL, Bernstein JJ, Santinelli S, Spelman LH, Miller LD, Arp LH, Anderson M, Barr M 1994: Canine distemper epizootic in lions, tigers, and leopards in North America. J Vet Diagn Invest 6: $277-288$

Barrett T 1999: Morbillivirus infections, with special emphasis on morbiliviruses of carnivores. Vet Microbiol 69: $3-13$

Beineke A, Puff C, Seehusen F, Baumgärtner W 2009: Pathogenesis and immunopathology of systemic and nervous canine distemper. Vet Immunol Immunopathol 127: 1-18

Deem SL, Spelman LH, Yates RA, Montali RJ 2000: Canine distemper in terrestrial carnivore: a review. J Zoo Wildl Med 31: 441-451

Frölich K, Czupalla O, Haas L, Hentschke J, Dedek J, Fickel J 2000: Epizootiological investigations of canine distemper virus in free-ranging carnivores from Germany. Vet Microbiol 74: 283-292

Kennedy S, Kuiken T, Jepson PD, Deaville R, Forsyth M, Barrett T, van de Bildt MWG, Osterhaus ADME, Eybatov T, Duck C, Kydyrmanov A, Mitrofanov I, Wilson S 2000: Mass die-off of Caspian seals caused by canine distemper virus. Emerg Infect Dis 6: 637-639

Lakatos B, Knotek Z, Farkas J, Ádám É, Dobay O, Nász I 1999: Adenovirus infection in cats. An epidemiological survey in the Czech Republic. Acta Vet Brno 68: 275-280

Munson L 2001: Feline morbilivirus infection. In: Williams ES, Barker IK (eds) Infectious diseases of Wild Mammals $3^{\text {rd }}$ edition. Blackwell Publishing, London, pp. 59-62 
Myers DL, Zurbriggen A, Lutz H, Pospischil A 1997: Distemper: Not a New Disease in Lions and Tigers. Clin Diagn Lab Immunol 4: 180-184

Piat BL 1950: Susceptibility of young lions to dog distemper. Bulletin Service d'Elevage Industrial Animales Afrique Occidental Francais 3: 39-40

Ramanathan A, Malik PK, Prasad G 2007: Seroepizootiological survey for selected viral infections in captive Asiatic lions (Panthera leo persica) from Western India. J Zoo Wildl Med 38: 400-408

Roelke-Parker ME, Munson L, Packer C, Kock R, Cleaveland S, Carpenter M, O'Brien SJ, Pospischil A, Hofmann-Lehmann R, Lutz H, Mwamengele GLM, Mgasam N, Machange GA, Summers BA, Appel MJG 1996: A canine distemper virus epidemic in Serengeti lions (Panthera leo). Nature 379: 441-445.

van de Bildt MWG, Kuiken T, Visee AM, Lema S, Fitzjohn TR, Osterhaus ADME 2002: Distemper outbreak and its effect on african wild dog conservation. Emerg Infect Dis 8: 211-213

Williams ES, Thorne ET, Appel MJG, Belitsky DW 1988: Canine distemper in black-footed ferrets (Mustela nigripes) from Wyoming. J Wildl Dis 24: 385-398 
Plate III

Konjević D. et al.: Canine distemper ... pp. 47-50

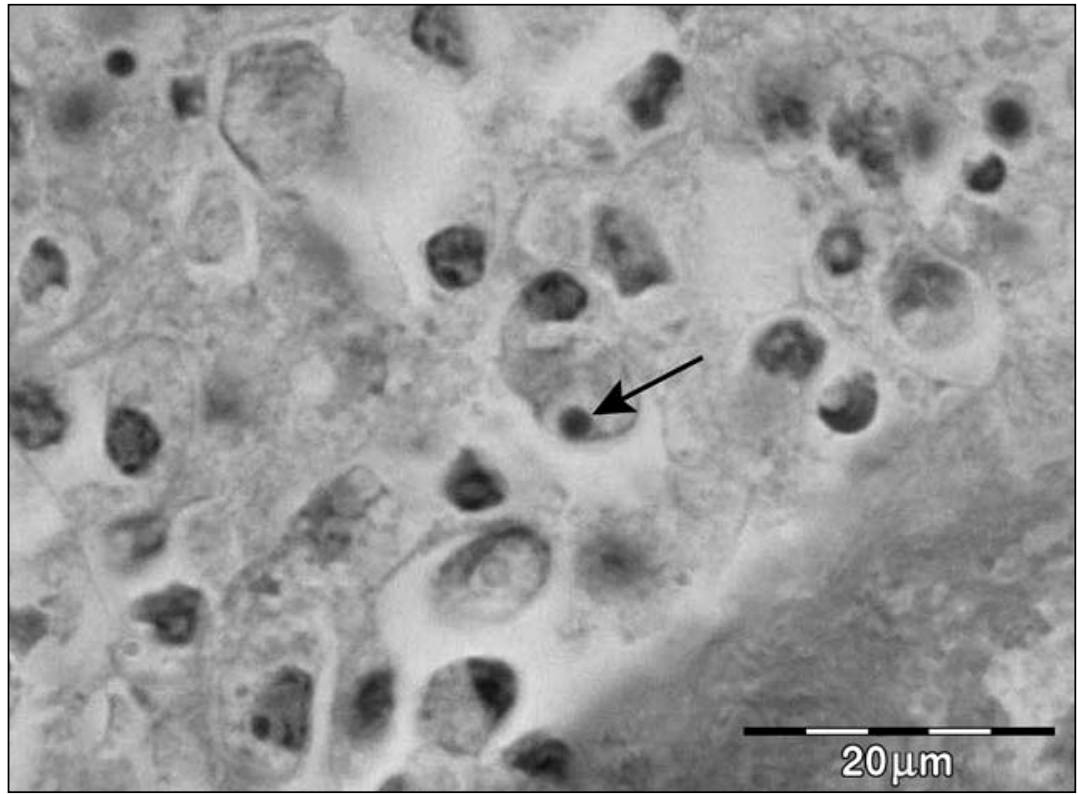

Fig. 1. Intestine. Inclusion bodies (arrow). $\mathrm{HE} \times 100$.

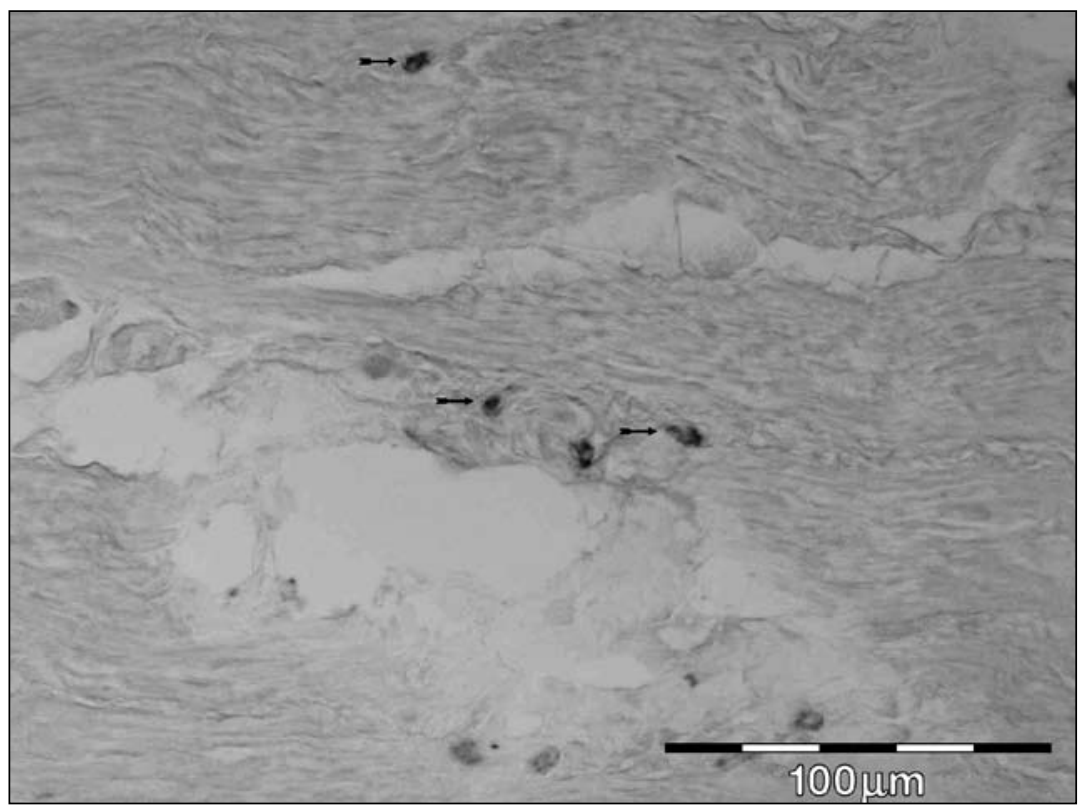

Fig. 2. Immunohistochemistry. Positive staining for canine distemper virus (arrows). 